\title{
Embracing the Agile Mindset: Faculty Perspective
}

\author{
Dr. Savitha $G R^{1}$ and Dr. Jai Raj Nair ${ }^{2}$ \\ $1 \& 2$ \\ Professors, Welingkar Institute of Management Development and Research, Bengaluru, Karnataka, India \\ Savitha.gr@welingkar.org,jai.nair@welingkar.org \\ 102 \& 103, Electronic City Phase 1, Next to BSNL Telephone Exchange, \\ Hosur Road, Bangalore - 560100, Karnataka.
}

\begin{abstract}
An agile mindset is about creating and responding to change in uncertain and turbulent environments. It's about thinking through how one can understand what's going on in the environment, identify what uncertainty one is facing and figure out how to adapt and go along.

Embracing an agile mindset in Higher Education is not an easy task. Educational leaders are currently facing complexity and growing expectation. Academic heads must catch up with the growth of higher-order competences for an everincreasing diversity of learners. In order to survive in the volatile environment, Management Institutions must adopt and embrace innovative pedagogical methods and technologies and also have to balance divergent interests and pressures from employees, regulatory boards and other stakeholders.
\end{abstract}

Challenged with these complexities, Management Education leaders need to be equipped with the capabilities to tolerate ambiguity, adaptively respond to change as it happens. In short, we need academic leaders to develop greater agility.

Keywords: Agility, Management Education, Innovation

\section{INTRODUCTION:}

In India, there is a rapid increasing of Management colleges and an exponential growth of Management Education aspirants. Even with high fee structure, lack of job opportunities and higher expectations from the employers, students aspiring to pursue Management Education is increasing. Hence Management Institutions are slowly facing a competition amongst themselves. To be in competition, institutions have to be agile and improve the quality of education and services that they provide to their stakeholders. Academic leaders know and embrace the realisation that improvement is not an event, but rather a collective journey of getting boosted all the time with no realistic end. The Covid-19 pandemic has pushed the Indian Education system to radically reinvent ways and means to embrace the 'new normal' and to implant refreshed perspective in the minds of its stakeholders. This research paper examines the preparedness of Management Education in embracing the Agile Mindset. 


\subsection{METHODOLOGY:}

The research study captures views and opinion on embracing agile mindset by Faculty of management education. The methodology adopted in this study was virtual focused group discussion. The data was collected from the structured questionnaire which was piloted and validated. The participants of the focused group discussion were faculty members who represented from various cadres like Assistant Professors, Associate Professors and Professors. In total there were 90 participants and Focused group discussion was done in three batches of 15 participants in each group, The discussion was for about 45 to 60 minutes. The researchers played the role of a moderator and meticulous note taker. This study was confined to the city of Bengaluru. The participants showed homogeneity in terms of recruitment, selection, training, courses taught in general and all of them belonged to private educational institutions.

In this research convenience sampling was used to draw conclusions from a sample and to generalize the results back to the population. From each of the institute a simple random sampling list was generated for faculty members. After in depth focused group study it was found that faculty members ready to cope up of with the change but expressed the need of training in developing virutal modules and certification programs. Management Institutions has been in need of transformation, long before the onset of the pandemic. There is an opportunity to rethink the traditional education system now. Digital learning is leading the charge as a sustenance, and many new trends are picking up momentum across Management Education.

A paucity of contemporary teachers has been a pressing challenge already, and it is growing more serious. Faculty are being called upon to redesign course content to meet the current and future needs. Moving away from traditional pedagogies in most average institutions, the demand for quality educators will shape the way Management Education moves forward from this crisis. Another major concern for management educational institutions is to provide competent faculty members in the required numbers.

The privatization has led to the increase in the number of institutions to match the supply of aspirants to that of the demand. However, in most cases, direction, relevance, and quality of management education has been questioned. Multidisciplinary and modular pedagogy that afford transferable skills and customised learning has started emerging. Post-pandemic times could see a blend of e-learning and mainstream face-to-face teaching in Management Education.

Opportunities for student mobility and practical exposure through exchange programmes, internships, participation in conferences, and more could likely be off the table for some time. Innovative new forms of collaboration and alternative paradigms are needed to drive learning, research and teaching. Sharing of knowledge between institutions globally through joint-teaching, virtual guest lectures, etc. could give students an enriched global perspective in these difficult times.

\subsection{REVIEW OF LITERATURE:}

López-Alcarria, A et. Al. (2019), concluded through their research that Agile Education has the potential to create a conducive environment for learning which would take care of improving the performance levels, satisfaction levels and motivation levels of faculty members and students alike which in turn will lead to building up long-term sustainable and responsible citizens.

Cubric, M. (2013), During the process of examining educational principles and theories that encourage Agile Education, Cubric noted that the perceived benefits of embracing an agile method in education can be allied to 
the empirical learning conjectures.

(Smith \& Sidky, 2009) suggested that the Agile Methodology is by large an assortment of ideologies and practices targeted towards augmenting teamwork that took its birth in the Agile Manifesto which defined Agile SDLC in the year 2001. In an Agile framework, teams give a lot of importance to individual articulation of their aspirations and targets, that often dwell upon dynamic workplans and fine-tuning them whenever the need comes up, providing a platform for genuine team interactions, enhancing group dynamics and boosting innovation by way of experimentation.

Galloway, 2012; Schwaber \& Sutherland, 2013 gave the opinion that Agile methods have indeed flourished with the passage of time, and the Agile practitioners have fostered many popular collaborative Agile software tools along with matching taxonomy. One of the most widely-used Agile method is Scrum that operates by encouraging cross-functional, self-managed teams to create work artefacts in small, incremental iterations called Sprints.

Royle and Nikolic (2016) opined that Agile has the potential to be easily customized to educational ecosystems despite the fact that there are obvious disparities between profit-motivated establishments and those like educational institutes that churn out lesser palpable end-products in the form of students.

Peha (2011), as a response to slackening progress in student attainment and dwindling educator morale in K-12 schools, sought to assist educational leaders become more effectual organizational leaders. Peha's recommended Agile Schools Manifesto explicitly asked for the prioritization of stake holder collaboration with the original Agile Manifesto propounded by Kent Beck and his team of 16 other software practitioners. In his argument generally favoring an Agile approach to K-12 education in a multitude of contexts, Peha specifically harped on its portability to educational institutions

Kamat (2012), made out a case for alterations in three core areas of educational function: Targeting mainly Engineering institutes, Kamat pointed out that as an addendum to enhanced learning, graduating students will make a smoother and seamless passage to the workforce (student to employee)- especially in fields like engineering where prospective fresh graduates who are already endowed with an 'Agile mindset' are highly in demand in the job market.

Royle and Nikolic (2016) largely suggested an Agile-oriented collective and cooperative method of work in educational institutions by using deliberate reflective planning and review methods. At the heart of Royle's and Nikolic's suggested methodology lies a prioritization by educators on the nurturing of students' skills and understanding instead of merely creating elaborate teaching/learning lesson plans. The Royle and Nickolic methodology suggests that for students and educators both, this categorical ordering of values translates to more fun for the learners, more independence and choices, and greater support and teamwork in the education ecosystem.

\subsection{THE APPROACH:}

Flexibility- Academia need to appreciate the capacity of students to be able to function in an ecosystem that is loaded with ambiguity and uncertainty. Learning, by itself, is a journey of discovery that progresses as students get more and more exposure to various situations and first-hand experiences. Hence, it is obvious that the prospects of creating new knowledge and contributing to the ever-growing body of knowledge becomes very bleak if one tends to become very rigid in their expectations. Thus, it has become imperative that the academic community adopt a flexible approach while catering to student needs instead of putting a blanket imposition of rigorous adherence to the stated academic curriculum 
including the syllabus. Similarly, they should also put efforts in nurturing the students in such a way that they can effortlessly find their way amidst uncertainty and flourish in an ever-changing dynamic world, where the only constant is change.

Teamwork - Teachers need to respect and adopt concerted approaches whereby the entire academic community join hands in a collective effort to achieve a desired outcome. Such teamwork calls for crystal-clear communication among all stakeholders in the teaching fraternity, which also includes good listening skills and the ability to furnish constructive feedback. It has become imperative for faculty to enable meaningful team interactions that require contribution, engagement and collaboration from each and everyone in the team. It is generally accepted that collaborative team-based approach far preponderates individual brilliance leading to better results. Moreover, once the students get hands-on experience in collaborative teamwork, they will be better prepared to become effective team members in their future professional and also personal lies.

Outcome-based Learning - Continuous and periodic assessments are an integral part of classroom delivery improvement and curriculum enhancement. However, assessments, per se, are not an end in themselves. Instead, the academic fraternity must endeavor to use such assessments predominantly as an instrument to further students' learning and their knowledge and skills proficiency in their respective domains. Educators must strive to remove the extremely short-sighted focus of students on how to go about getting a good grade and instead, make them have a long-term focus on how their current learning (knowledge and skills both) can be made more application-oriented so that they can harness them in all their future undertakings and endeavors. Faculty members should realize the importance of motivating students to move from an assessment-driven approach to a learning-driven approach. Hence, the faculty members have a key role to play in nourishing self-motivated, learners for life.

Curiosity-driven Education - The world over, the academic fraternity, regardless of the domains they come from universally accept that that acquisition of knowledge via learning happens best when students are themselves engrossed, involved, and inspired to learn. It is an accepted fact that often the inspiration to learn something comes as a result of unanswered questions and new problems which students face down the line resulting in their inclination to investigate further. Thus, the educators have to actively and collectively support student empowerment and idiosyncrasy by making them take up various assignments through which they can learn a lot and also facilitate experiential opportunities in the realworld, whereby they can get first-hand experience. It is probably true that experience is the best teacher. Knowledge engineering transpires when students take into account perspectives, ask new questions and exploit their own intonations as they continuously immerse themselves in varied study material leading to honing of their pertinent skills.

Exposition- As domain experts, faculty members are aware that the body-of-knowledge within their specific bailiwick is continuously growing and in certain fields they are also rapidly expanding. It is important for academia to generate continuous opportunities for students to not only master domain knowledge but also to use their learnings and skills as they gain them. Once students are able to demonstrate tangible testimony of their accomplishments, they develop self-confidence, get into deeplearning mode and are able to preserve that learning for a much longer duration. This makes them more suitable for adapting to the changing needs and demands of time. Faculty members should rejoice when they become successful; and some indicators for success could be - a sharp rise in graduate placement, lateral employment opportunities, and increased salaries year-on-year. They should celebrate rival institutes try to imitate their techniques in the hope of similar results.

Dynamic and Continuous Improvement- As teachers, faculty members must aim for nurturing learning 
eco-systems that promote creativity, innovation and risk-taking mindset. In order to achieve this, the educators must continuously evaluate their present teaching pedagogy and should be ready to come out of their comfort zones and experiment with new methods. This would be a great boon for the students who would get an environment where they would not feel diffident to try out new ideas even at the cost of failing. A lot of learnings can be garnered from failures and also from frequent evaluations and constructive feedback. This learning is applicable to both faculty and students. It is the conviction of faculty members that a high-class education can make significant connections from the current to the future and is grounded in the experimentation skills that foster confidence and an inclination to be innovative.

\subsection{CONCLUSION:}

Academic leaders know that they must work through the education system that they have, and take their stakeholders on a journey of long-term behavioural and cultural change. They pursue a path of radical incremental change. It is incremental because it grows out of the current strengths of the Management Institution. Academic leaders are continually working out how to create powerful learning approaches that build on and leverage the best of the past and radical changes in pedagogical designs over time.

Approach to leading improvement would work well when academic leaders look for solutions to well-known problems in standardized contexts. But that's not the task facing academic leaders in today's scenario. They are working in a kind of eco system which is filled with complexity and ambiguity where the problems and solutions are not clear, and there are no ready-made solutions that can simply 'plug-and-play' as in standard contexts.

The agile mindset is crucial to the system of Management Education. Deep down agile leaders know and embrace the realisation that improvement is not an event, but rather a collective journey of getting better all the time. So let's hope that academic leaders become agile to crea te greater impact.

\section{References}

1. López-Alcarria, A.; Olivares-Vicente, A.; Poza-Vilches, F. A Systematic Review of the Use of Agile Methodologies in Education to Foster Sustainability Competencies. Sustainability 2019, 11, 2915.

2. Cubric M. An agile method for teaching agile in business schools. International Journal of Management Education. 2013 Nov;11(3):119-131. https://doi.org/10.1016/j.ijme.2013.10.001

3. Greg Smith, Ahmed Sidky., Becoming Agile: ...in an imperfect World, 2009, Manning Publications Co., ISBN 1933988258, 9781933988252

4. SCHWABER, K. \& Sutherland, J. (2013). The Scrum Guide ${ }^{\text {TM }}$. Scrum. Scrum.org, July.

5. Royle, Karl \& Nikolic, Jasmina. (2016). What we can learn from Agile Work Practices about Learning and Teaching in Schools.. 10.13140/RG.2.1.3501.0161.

6. Steve Peha, Agile Schools: How Technology Saves Education (Just Not the Way We Thought it Would), InfoQ, June 28, 2011.

7. V. Kamat, "Agile Manifesto in Higher Education," 2012 IEEE Fourth International Conference on Technology for Education, Hyderabad, 2012, pp. 231-232, doi: 10.1109/T4E.2012.49. 

*** 